Please do not remove this page

RMIT

UNIVERSITY

\title{
The art of ethnography: the aesthetics or ethics of participation?
}

Hjorth, Larissa; Sharp, Kristen

https://researchrepository.rmit.edu.au/esploro/outputs/9921859552401341/filesAndLinks?institution=61RMIT_INST\&index=null

Hjorth, L., \& Sharp, K. (2014). The art of ethnography: the aesthetics or ethics of participation? Visual Studies, 29(2), 128-135. https://doi.org/10.1080/1472586X.2014.887261

Document Version: Accepted Manuscript

Published Version: https://doi.org/10.1080/1472586X.2014.887261

Repository homepage: https://researchrepository.rmit.edu.au

(C) 2014 International Visual Sociology Association

Downloaded On 2023/04/26 10:27:47 +1000

Please do not remove this page 
Thank you for downloading this document from the RMIT Research Repository.

The RMIT Research Repository is an open access database showcasing the research outputs of RMIT University researchers.

RMIT Research Repository: http://researchbank.rmit.edu.au/

\section{Citation:}

Hjorth, L and Sharp, K 2014, 'The art of ethnography: the aesthetics or ethics of participation?', Visual Studies, vol. 29, no. 2, pp. 128-135

See this record in the RMIT Research Repository at:

https://researchbank.rmit.edu.au/view/rmit:24395

Version: Accepted Manuscript

Copyright Statement: ㄷ 2014 International Visual Sociology Association

Link to Published Version:

http://dx.doi.org/10.1080/1472586X.2014.887261 


\title{
THE ART OF ETHNOGRAPHY: The Aesthetics or Ethics of participation?
}

Larissa Hjorth and Kristen Sharp (RMIT University)

\section{E: larissa.hjorth@rmit.edu.au}

\begin{abstract}
When Hal Foster noted an ethnographic turn in the artworld in the 1990s he was eluding to broader 'impulses' that had haunted avant-garde movements throughout most of modernism such as surrealism (1996). However, the ethnographic turn didn't just impact the visual arts-areas such as Cultural Studies felt a shift from the textual towards the ethnographic. Two and half decades on, the pervasive nature of ethnography can be felt across the disciplines as ethnographic approaches evolve, migrate and transform (Pink 2006, 2009), especially through the growing ubiquity of the digital. In this context, various entanglements need to be defined-especially the drawing upon ethnographic aesthetics and ethics in art practice. But is this ethnographic compulsion just a stylistic trend or does it speak of deeper concerns in the arts about engaging with social and cultural practices and reflexive participation? Drawing on case studies in contemporary art, this paper focuses upon the haunting of the ethnographic turn in art through numerous guises from relational aesthetics onwards.
\end{abstract}

\section{INTRODUCTION}

Ethnography, as the writing up of cultural practice, has, much like culture itself, taken on various manifestations. Once a method used by sociologists and anthropologists, ethnography is now a widely deployed approach and conceptual framework in contemporary media cultures. Throughout this evolution, some concepts have remained central to ethnographic practice - the reflexive negotiation of self, power, labour and participation. Given these key concerns, it is not surprising that ethnography — as a way in which to frame cultural practice- has been embraced within the visual arts. In particular, the significant increase of socially-engaged practices in late twentieth-century art-identified in the 1990s by Hal Foster in 'The Artist as Ethnographer' (1996) and Nicolas Bourriaud's 'Relational Aesthetics' (1998 [2002]) — foregrounds art as a social/cultural encounter. 
For more than a decade the legacy of relational aesthetics has continued to take various guises in what Bourriaud defined as artists' impulse to take human and social relations as the context and content for art production and consumption. According to Bourriaud, contemporary art needed to stop hiding behind 1960s philosophies and strategies and instead engage with emergent internet cultures and the focus on user co-creation, participation, collaboration and DIY (do-it-yourself). In relational aesthetics the audience is a community to be collaborated to create intersubjective encounters.

However for critics such as Clare Bishop (2004), relational aesthetics was more of a "curatorial modus operandi" whereby the "laboratory" experience of the gallery encounter doesn't openly address the imbalances of power relations that in turn lead to various uneven forms of participation. For all its legacy and systematic problems relational aesthetic has identified a key ongoing tendency in contemporary art - the deployment of the ethnographic. With reflexivity and participation being central tenors in relational aesthetics it is no surprise that the haunting of the ethnographic, and art's perpetual appropriation and misappropriation should come to the forefront. Yet over a decade later since relational aesthetics has the artworld moved onto more sophisticated understandings of ethnography? In sum, has ethnography moved beyond an aesthetic gesture towards an ethical practice in art?

Ethnographic probing - specifically reflexivity and redefining participation - have featured in the movement of the visual arts towards increasingly localised, social and political encounters. With more artists travelling and participating in residencies "elsewhere", art and the ethnographic have increasingly become bedfellows. Here the ethnographic in art should not be mistaken for documenting but rather it is a type of method and criticality. It is about repositioning participation and its relationship between maker and the audience, a relationship that has increasingly been challenged with the rise of the professional amateur (pro-am) and the producing user (produser). If contemporary media culture is characterised by participation and collaboration, then this challenges art to move beyond a mere of adoption of internet terminology (as in the case of relational aesthetics). This shifting media scape has given way to the need, if not compulsion, for art to evoke the ethnographic; this particularly significant given the ways in which ethnography has become an important approach in 
understanding digital and online spaces (Boellstorff et al. 2012). The ethnographic can help the artist/curator probe the culture context, providing a nuanced space for the audience and artist to reflect. But is art's adaptation of the ethnographic about a criticality and reflexivity or is it a mere aestheticisation of ethnographic? Is it a style or a politic?

In this paper we map the rise of ethnographic approaches in contemporary art and the types of challenges it presents. The role of a critical reflexivity in art/ethnography is examined as well as the changing practices of art/ethnography in relation to digital mediation, particularly the changing topography of understanding place in light of online/offline relationships which emphasis symbolic as much as geographic ideas of place. The analysis of this intersection is especially valuable in light of the participatory assumptions often made around social media (and earlier, the internet itself).

In order to do so we firstly we explore the entanglements between identity, ethnography and place. In this section we reflect upon how ethnography has shaped, and been shaped by, phenomenon such as digital media. We then consider the specific role ethnography occupies in contemporary art practice. We then move onto two case studies of art projects that demonstrate different guises of the ethnographic. We then conclude with further questions.

\section{ETHNO-GEOGRAPHIES: The Place of Ethnography today}

Much of the debate around the whether the deployed of ethnography by the artworld is a mere aestheticisation or a tactic can be traced more recently to the identity politics so prevalent in the artworld in the 1990s. For Lee Weng Choy the 1990s identity politics has taken a slightly different guise in what he calls the 'ethno-geographic'an aesthetic that graces many contemporary art galleries around the world (2011). Far from the rise of globalisation rendering the world into a McLuhan 'global village', identity politics has become entrenched in the entanglement between geography and ethnicity. As Lee notes,

..."identity" continues to underpin so much of how art is being presented. In terms of biennale curating, it's as if it's part of the very grammar and logic of these productions. Geography and ethnicity are privileged in biennales, to the 
extent that one could describe their mode of knowledge as "ethno-geographic". Look at the Asia Pacific Triennial, for instance. In the first, in 1993, Japan was the star, then came China. In the last, North Korea, Cambodia, these were the new attractions. The last thing I want to do is criticise the APT along these lines. What I want is to better understand the ethno-geographic logic of biennale curating, so that we might "think globalisation" more clearly (2011: 254).

What becomes evident in this argument is the need to rethink place as not just geographic and its relationship to multiple forms of presence. Given the emphasis on participation and collaboration in both contemporary art and media practices, ethnography has taken on new importance as a way in which to grapple with changing notions of place. In the face of the 'mobile' and 'intimate' turns over a decade ago that are epitomised by the ubiquity of mobile media, how place is experienced, recorded and articulated has changed dramatically. From the shift of printed maps to online, mobile GPS maps, the overlays of information and place as 'stories so far' (Massey 2005) has changed. This has led theorists such as Anne Beaulieu to note that ethnography is no longer concerned with co-location but rather co-presence (2010).

This movement from understanding place as a location to a space for various forms of presence (co, net, tele, absent, ambient) is essential to both contemporary art and ethnographic practices. Here we need to acknowledge that intimacy and presence have always involved forms of mediation - if not by memory, then language and gestures. And it is at the site of interrogating multiple modes of presence and the overlays of place that art ethnographies are most successful: moving beyond a mere aestheticisation and becoming an embodied part of creative, social practice.

With the rise of technologies in an increasingly mobile-physically and technologically_place has become progressively more contested. As Rowan Wilken and Gerard Goggin note in Mobile Technologies and Place, place is one of the most contested, ambiguous and complex terms today (2012: 5). Viewing it as unbounded and relational, Wilken and Goggin observe, 'place can be understood as all-pervasive in the way that it informs and shapes everyday lived experience-including how it is filtered and experienced via the use of mobile technologies' (2012: 6). As social 
geographer Doreen Massey notes, maps provide little understanding into the complex elusiveness of place as a collection of 'stories-so-far':

One way of seeing "places" is as on the surface of maps... But to escape from an imagination of space as surface is to abandon also that view of place. If space is rather a simultaneity of stories-so-far, then places are collections of those stories, articulations within the wider power-geometries of space. Their character will be a product of these intersections within that wider setting, and of what is made of them... And, too, of the non-meetings-up, the disconnections and the relations not established, the exclusions. All this contributes to the specificity of place (Massey 2005: 130).

In this section we suggest that 'Ethno-geography' provides a productive way to think about how art shapes, and is shaped by, localities and regions across the world. The pre-fix, 'ethno', locates people at the centre of geographic practice, much like Benedict Anderson's imagined communities (1991). Moreover, it evokes the spirit of ethnography as being an important part in the construction of place. With the 'geo' wedged in between 'ethno' and 'graphy' a new way to think about, and narrate, place is provided. Here we are thinking about place as a concept that is lived and imagined, geographic as much as conceptual. Social geographers like aforementioned Massey or anthropologists/phenomenologists like Tim Ingold (2008) are really useful in sketching the complex narratives constructing place. As Massey observes, a sense of place is more than a physical, geographic experience (2005). That is, place as a space that is not only geographic and physical but evokes cartographies of the imaginary, emotional, mnemonic and psychological. For Ingold, place is a type of entanglement which is shaped by movement, or what Ingold calls a 'meshwork' of moving things (2008).

Visual and sensory ethnographer, Sarah Pink, takes this development of theories of place a step further in arguing that we are moving from a period of networked visual events to emplaced images (2009). In her theory of 'multisensoriality', Pink invites us to understand movement and place-as-event. If we apply this model to the artworld and its role in constructing, and being constructed by, place-as-event (a.k.a. post relational aesthetics) we can begin to define new ethno-geographies. The oscillation between viewing social cartographies in art practice as either ethno-geographies or 
geo-ethnographies reflects the need to centralise the question of place in this discussion.

By focusing upon geo-ethnographies we can rethink ethnography and art practice now almost three decades on from Hal Foster's famous essay 'The Artist as Ethnographer' (1996) in which he overtly toyed with Walter Benjamin's 'The Author as Producer' (1934). In Foster's essay his use of ethnography is relatively fixed to the discipline of anthropology, especially 'classic' anthropology which has been guilty of reinforcing notions of 'otherness' always at the surface of art discourses (Clifford \& Marcus 1986). In his savage critique of what he sees as quasi-anthropology in art movements such as surrealism, he questions the relationship between art and ethnography.

Drawing from one example, Foster discusses how an international site-specific artist is flown into a context in which they quickly must 'collaborate' and 'engage' with the local community to make the work. In an obvious instance of what Nikos Papastergiadis calls 'reflexive hospitality' (2012) whereby the artist, despite his or her best intentions, makes the work often without engaging in what Foster identifies as basic

ethnographic participant-observer's relationships, let alone offering any critique... Almost naturally the focus wanders from collaborative investigation to "ethnographic self-fashioning" in which the artist is not decentred so much as the other is fashioned in artistic guise (1995: 306).

Here Foster calls on ethnography as a way in which the artist can be reflexive to their own assumptions in order to delving into the muddy waters of collaboration in which power, labour and subjectivity come under question. One of the key ongoing factors, of which ethnographers need to be continuously reflexive, is their role in participation. After all, "cultures ... [do] not hold still for their portraits" (Clifford \& Marcus 1986). In the Annual Review of Anthropology (2010), Gabriella Coleman reviewed ethnographic approaches to digital media, dividing this work into three broad and overlapping categories: (a) research on the relationship between digital media and the cultural politics of media; (b) the vernacular cultures of digital media; (c) the prosaics of digital media. It is the last point, the emphasis on the commonplace, the unromantic, and the quotidian that is probably the most notable aspect of ethnography. In the 
1990s relational aesthetics tried to evoke these aspects by emphasising the sociocultural dimensions of art practice, but often became little more than the aforementioned 'reflexive hospitality'. Hence, by re-examining ethnography, and particularly ethnographic approaches, the place of art might be able to negotiate the politics of everyday as dynamic and yet prosaic.

In a recent special issue of Media International Australia, the editors map the history, interdisciplinary formations and changes of ethnography (Horst, Hjorth \& Tacchi 2012). Unlike art, which had its ethnographic turn in the 1990s, ethnographic studies of media and consumption emerged in the late 1980s in the UK (Morley 1992; Silverstone 1990; Silverstone \& Hirsch 1992). Ien Ang's research into the ethnographic turn in media and cultural studies was key in addressing the role of active, heterogeneous audiences (Ang 1991). In media sociology, Roger Silverstone (1990) called for a move towards an anthropology of the television audience, with a methodological approach that views the individual in the context of the everyday and takes account of the home, technologies and neighbourhoods as well as public and private mythologies and rituals (1990: 174). This focus upon the contexts of use signalled a shift away from a previous focus upon typologies of individual users that often ignored the situated complexities of everyday life (Morley 1986).

For Virginia Nightingale (2012) the development of media ethnography with the cultural or 'reflexive turn' in anthropology led to improved ethnographic practice in media and cultural studies, and the expansion of media anthropology. This is also the moment when anthropology began to focus upon carrying out research 'at home' in Western and middle class contexts where media of various forms had become pervasive. Coinciding with the rise of digital and mobile media in which the home became increasingly unbounded (Hartman et al. 2009), the rise of digital and media ethnography sought to address this phenomenon (Boellstorff, Nardi, Pearce \& Taylor 2012; Horst \& Miller 2012). While this digital/online turn marks a shift from colocation to co-presence, the role 'participant observation' is remains central to rigorous ethnographic practice.

In light of this shift towards co-presence, how might ethnographic approaches, given the focus on analysing participation and reflexivity, help us reimagine art practice in 
the twenty-first century? Specifically, how might the artworld utilise ethnographic approaches to reimagine the identity and place as something contested, dynamic and contingent-beyond just invoking Foster's quasi-anthropology? For example, how are notions like participation and community revised? In the next section we outline how ethnography is being conceptualised in art today and then move onto a case study of two different art projects deploying ethnographic methods.

\section{BEHIND THE SCENES: An ethnographic approach to Art}

In this paper so far we have focused upon ethnography within other disciplines such as media, online and cultural studies. As we have noted, the migration of ethnography across disciplines such as anthropology, sociology and digital culture has seen the definition of ethnography as both a method and a theoretical probe, transform. In art, the same can be seen with some of the specific debates around ethics versus aesthetics not replicated in other disciplines. Grant Kester's recent work on art collaboration The One and the Many (2011) provides a useful framework for understanding the structure and reciprocal relations of this type of collaborative production. Collaborative methods establish different forms of inter-subjective affect, identification and agency (Kester 2011: 68). This subsequently requires new forms of documentation and critique of artwork beyond an analysis of the 'finished' work or the 'singular' participatory event in order to capture the social and ethical relationships between artists and participants, the structures of operations and relations of power in collaborative practices. These methods borrow heavily from ethnography and have opened up debates regarding the weight given to ethical concerns over aesthetic judgements in the evaluation of art (Downey 2009).

Kester's exploration of the ethical dimensions of ethnography's role in art has been criticised, most notably by Claire Bishop (2006a, 2006b; see also Kester 2006), for over-emphasising ethical dimensions of participatory practices and 'good intentions' over aesthetic considerations. Whereas Bishop is interested in the political outcomes of participatory practices and ability to disrupt and provoke following from early and late twentieth-century art practices. In this paper our focus is not to rehash wellknown debates, but rather to use Kester's critique as a way to look at how recent socially-engaged art practice has the capacity to offer methods for re-imaging art 
practice and the borrowing of ethnography beyond being an 'aesthetic playfield" (Kester 2010).

Moreover, different models of presentation and writing about collaborative projects to make these processes explicit and to include them as part of the outcomes of projects, including exhibitions, are required (Ashford, Ewald, Felshin \& Philipps 2006). Such methods would utilise a combination of participatory modes of observation and documentation, such as multi-modal forms of documentation including, video, stills and on-line critically reflective writing during the process. Such 'embedded' process need to be cognisant of the importance of critical reflection around subject-object positions and trying to delineate 'insider/outsider' perspectives. Online social media is a useful format for this as it enables a range of easily accessible modes of presentation and access, and it is very much focussed on 'being present' rather than only providing archives or historic repositories of information.

This requires the adoption of a reflective practice-led research method, which involves the researcher as an active partner in the collaborative project observing, documenting, reflecting upon and then presenting the social nature of creative knowledge production. This acknowledges the imaginative and creative elements involved in this form of research. This method, acknowledging a collaborative dynamic between researchers and the subjects of study, has been an important method in ethnographic research since the 1960s (Lassiter 2005; Foley \& Valenzuela 2005). In an art context it creates an approach whereby the researcher is embedded with the artists in developing techniques for documenting and presenting the process of collaboration.

Through the prism of online and mobile media, documentation of the project in process can provide artists and publics with the ability to reflect and participate in different ways. But the key issue here is not to render the online as a caricature of the offline. Rather, while it mirrors and amplifies some of the offline subjectivities it is also a co-present place with its own localised geographies and socialities that need to be attended to. There is significant potential here to harness the influence of social media in constructing intimate engagement with art and the performativity of the political, and engaging with audiences beyond physically locative practices of such 
face to face structures. As we discuss in the next section through two case studies, the deployment of ethnographic methods can lead to interesting types of collaboration but can also easily lead to a mere aestheticisation of the ethnographic.

\section{CARTOGRAPHIES OF ART: Spatial Dialogues and the $5^{\text {th }}$ Auckland Triennial}

Contemporary global cultures are characterised by a new cartography of human volition - transnational travel, migration, and evolving networks of community and communication. This is particularly the case in the artworld, where artists are increasingly mobile, circulating and engaging in transnational and transcultural experiences as a form of global cosmopolitanism (Meskimmon 2010). One of the challenges for art, as a result of these processes, is how to respond and adapt to the reconfiguring of identities and practices.

As an increasingly visible area of contemporary art practice (Storer 2009; Bishop 2006a), collaboration provides an important method for engaging this changing landscape. It creates opportunities for experiencing and understanding the key relations and tensions arising in globalisation, particularly those of individual identity, knowledge production and cultural difference. What is significant here, is that unlike Foster's concern with art's potential adoption of the Eurocentric desire for engaging and representing the 'other', the contemporary art environment is one in which artists engage in trans-national projects which allow for a constant traversing of cultures and identities - indicative of the mobile contemporary and part of an increasingly digital world. This is something that Miwon Kwon identified when highlighting the contemporary sense of being "out of place" and "not at home" (Kwon 2000 cited in King and Hanru 2013). Or, it can be viewed as what aforementioned Lee called geoethnographies.

One example of this type of de-essentialised approach to place and identity emerged in the recent transnational project Spatial Dialogues: Public Art and Climate Change. ${ }^{l}$ The project explored how contemporary public and mobile screen-based art can combine to contribute to an international dialogue on the environmental and cultural significance of water ecology in the context of climate change. While it physically manifests across three cities in the Asia-Pacific region-Melbourne, 
Shanghai and Tokyo - its approach emphasises a de-centred discourse on the environment.

For example, rather than just focusing on artists in one location, the project works across sites in Melbourne, Shanghai and Tokyo and through the co-presence of online social media, it created audiences who are also mobile, albeit virtually, across these spaces as well as new audiences who are interested in art from the region. Rather than considering social and mobile media as just another site to replicate content from the offline components, Spatial Dialogues made mobile media experiences built around the experiences of everyday users. ${ }^{2}$ The importance here was to utilise existing social mobile media networks and to view it as a parallel co-present place for creativity and exploration. That is, media as a space for reflexive participation rather than just another co-present platform for the same content.

In Underground Streams: Shibuya, a Spatial Dialogues and the Boat People Association $^{3}$ collaborative event in Tokyo, artists were invited to engage the public in dialogues and reflections on the changing urbanscape of Tokyo, specifically the burial of the Shibuya River underground. The river has been redirected and channelled beneath the concrete roadways of Tokyo (see Milner 2013). One of the last sections was covered over in the late 1960s. This urban erasure of what was once a significant conduit for local identity and productivity has changed the meaning of place and identity. One of the aims of Underground Streams was to generate dialogue, with some aim of socio-political transformation, to recognise and acknowledge the way that urban transformation impacts on human/nature interrelationships and local ecologies, and the changing role and identity of urban rivers.

While artists in Underground Streams produced a number of different works for the project ranging from performance and mobile gaming, to socially collective activities (walks alongside the covered river), community activities such as lantern making, and video and sound documentation - they collectively produced a symbolic dialogue on the meaning of water and river ecologies in urban space which stretched across art and into urban planning and social activism. The works were largely seen as conversations in process, unfolding discussions, opening portals for public disburse online and offline. The 'public' here is not some generalised amorphous mass, but 
rather local residents and passing consumers (the project was based in a park [Jingudori Koen] in Shibuya_one of Tokyo's highest density shopping region). As with many socially-engaged, participatory or 'relational' artworks the emphasis was not on art as a centralised fixed object, but rather as a structure through which dialogue is encouraged. The aim is to uncover and allow for the diverse identities of the river, current and historic, to emerge. While there are similarities to earlier practices in activist and community art, particularly that which rose to prominence in the 1970s and 1980s, the type of public engagement facilitated through Spatial Dialogues appears less focussed on a specific political outcome-such as a direct form of urban transformation, or community building-and more about allowing for aesthetic as well as socio-cultural reflection about the changing environment of the city.

Rather than aiming for some essentialised 'truth' to emerge about the identity of the river, what emerged was a plurality of perspectives from locals reflecting on their encounters with the river in its past uncovered state, to others discovering that a river existed in the area at all, to re-imaginings of the space through dance, food, mobile gaming and live performance. ${ }^{4}$ This type of open structure encouraged participantsartists and otherwise - to apply their own cultural lenses to identities of place. Many of the artworks (such as Shibuyagawa Ekimae [Hidden River]) were reliant on common forms of ethnographic practice-video documentation, soundscapes, observation and open-ended interviews - to emphasise interpretative narratives and subjective encounters to re-imagining a place. A mobile game, keitai mizu, using Twitter and Instagram allowed players to become investigators in finding the underground streams through artwork clues. Through the intertwining of online and offline spaces the park became a space for play, discovery and creativity. In this way these projects reinforce Papastergiadis's emphasis on site as much a conceptual as geographic entity for artists: '... the artist does not simply dwell in a place but collaborates with place.' (Papastergiadis, 2011: 88). In the case of the Underground Streams project this interaction can then exist as site-specific responses and imaginative encounters, online and offline, across spaces and cultures.

The rise of regional biennales, collaborations and transnational projects since this 1990s - facilitated through cheap travel and technologies of communication - are challenging and reformulating the methods and structures used to understand and 
analyse art. Echoing the counter-artefact and political philosophies of many 1960s art movements (i.e. situationalist), contemporary art practice has continued to focus upon the socially-engaged interventions, which privilege collaboration and participation, over conventions of object-based creative practice. A recent example is The Lab curated by Hou Hanru as part of the $5^{\text {th }}$ Auckland Triennial 2013 If you were to live here.... The Lab is set up as a research site within the Triennial. While it exists in a conventional gallery exhibition context, the aim is to create a space inside this for an open curatorial structure and model of operation. The emphasis is on interaction, transformation and being a "living" entity (King and Hanru 2013).

This kind of emphasis on the social space of art is typical of contemporary art practices that challenge conventional exhibition structures and conventions to become creative sites of production more open to discursive transformations and interactive productions. Art in this context becomes a "living process" (aucklandtriennial.com) that seeks to tap into local networks and voices. However, at the same time, rendering the biennale space into a "lab" or "incubator" can also be viewed as just a stylistic trend in art production whereby the act of being "discursive" can become an aesthetic. Returning to Bishop's criticisms of relational aesthetics and its deployment of the "lab" without examining the uneven power relations involved, one wonders how curator Hanru can move the idea of the lab away from such a legacy.

For example, while the 'Transforming Topographies' project in The Lab was intended as a space of conversation, which encouraged reflective and 'open' conversations about changing urban topographies, it remained a one-way conversation. In that once again, while the public was invited to participate and these actions were documented through photography, interviews and video ${ }^{5}$ there was little advancement beyond the borrowing of conventional anthropological documentations, nor was there evidence of a space that facilitated critical reflection on the process- thus it became like a closed loop. 'Real' urban transformation remained something that could only be documented and brought back into the gallery to be presented, rather than something that was taken beyond the gallery and enacted. Despite the rhetoric expounding change and openness there seemed a rigidity of process and presentation borrowing from anthropology that offered little in the way of a reflexive feedback into practice. 
Some artists did address this issue for openness through social media and online sites which enable greater reflection on the process of their engagements and practices; for example, Ou Ning whose Bishan Commune project was part of the Triennial. The project itself exists beyond the space of the Triennial and the online blog outlines in far more detail and rigour the actions of the project (a rural reconstruction project in China $^{6}$. These types of online spaces allow for the type of 'living' dialogue that the still largely static triennial/biennale format is seeking to replicate.

In If you were to live here the intention was to revisit the idea of triennials (and similar types of exhibitions such as biennials) as a "multidisciplinary and performative event to engage global creators with real life where it takes place'. 7 An ambitious if somewhat overly-broad aim raising questions as to the idea of 'place' and where the act of art or encounters with art take place. The Triennial did allow for a reimagining of the 'place' of art in the urban-both geographically and conceptually, and the role of creativity within local contexts. It allowed art to be considered as a 'living' changeable event rather than a fixed and unchanging object, and the gallery to be seen as something that is part of a networked rather than a closed off rarefied space in which the 'other' (in this case 'real life') is represented. Here art became a lens through and in which to re-imagine the city. However, because the 'place' and context of art remained in conventional art institutions and galleries and thus did not push the encounters into uncomfortable terrain it became an aestheticisation of ethnographic ethics. Thus, art's ability to facilitate a deeper and more critical reflection on the ethnogeographic and on its own methodologies of practices remains an exception rather than the rule when it comes to current practice.

\section{CONCLUSION: Placing art in Ethnography}

Like the ethical issues facing socially-engaged practices of art, one of the key challenges in using ethnographic research is understanding how place and presence can be entangled and overlaid in different ways across the online and offline, here and there, now and then. Returning to Boellstorff's et al. (2012) observation, whether online or offline negotiating co-location or co-presence, the role of participant observation' is central to rigorous ethnographic practice. There is a need for more 
rigorous understandings and deployments of ethnography as a method in the arts mere procedural documentation (i.e. photos) do not equate to ethnography. This situation is particularly prevalent within the arts with the rise of socially-engaged projects that tend to be merely stylistic or aesthetic, rather than critically and reflexively, engaged.

In this paper we have reflected upon some of the many changes in the relationship between art and ethnography. We have traced how ethnography has become a multivalent set of methods and conceptual frameworks across the disciplines. We have then turned to ethnographies' current formation in the arts through debates around Kester's work. We then moved to two case studies that deployed various forms of the ethnographic as both an aesthetic/style and ethic to flesh out some of the many issues at stake. Hopefully we have shifted the discussion away from Foster's damning critique and provided a space in which the haunting manifestation of the ethnographic in contemporary art can be reflected upon. Far from definitive, we have suggested that ethnography can provide contemporary transnational art collaborations with greater insight and rigour. 


\section{References}

Anderson, B. 1983. Imagined Communities: Reflections On The Origin And Spread Of Nationalism, London: Verso.

Ang, I. 1991. Desperately Seeking the Audience, Routledge, London.

Ashford, D., Ewald, W., Felshin, N., \& Phillips, P. C. 2006. A Conversation on Social Collaboration. Art Journal, 65(2), 58-82.

Auckland Triennial, Auckland Triennial, www.aucklandtriennial.com, accessed 5 July 2013.

Ashford, D., Ewald, W., Felshin, N., \& Phillips, P. C. 2006. 'A Conversation on Social Collaboration'. Art Journal, 65(2): 58-82.

Beaulieu, A. 2010. 'From Co-location to Co-presence: Shifts in the Use of Ethnography for the Study of Knowledge'. Social Studies of Science, 40 (3): June. 453-470.

Bishop, C. 2012. Artificial Hells: participatory art and the politics of spectatorship, London: Verso

Bishop, C. 2006a. 'The Social Turn: Collaboration and Its Discontents,' Artforum, February, pp. 179-185

Bishop, C. 2006b. 'Reply' Artforum, May, pp. 22-23.

Bishop, C. 2006c. Participation, London: Whitechapel.

Bishop, C. 2004. 'Antagonism and Relational Aesthetics.' October (Fall No. 110): $51-79$

Boellstorff, T., Nardi, B., Pearce, C. and Taylor, T.L. 2012. Ethnography of Virtual Worlds: A Handbook of Method, Princeton University Press, Princeton.

Bourriaud, N. 2002. Relational Aesthetics. Dijon: Les presses du réel. First published in French 1998.

Burgess, J., \& Green, J. 2009. YouTube: Online Video and Participatory Culture. Cambridge: Polity.

Clifford, J. \& G. Marcus. 1986. Writing Culture: The Poetics and Politics of Ethnography, London: University of California Press.

Coleman, G. 2010. 'Ethnographic Approaches to Digital Media', Annual Review of Anthropology 39: 487-505.

Downey, A 2009. 'An Ethics of Engagement: Collaborative Art Practices and the Return of the Ethnographer' Third Text, Vol 25: 5, September, pp. 593-603.

Foley, D., \& Valenzuela, A. 2005. Critical Ethnography: The Politics of 
Collaboration. In N. K. Denzin \& Y. S. Lincoln (Eds.), The Sage Handbook of Qualitative Research (Third Edition ed., pp. 217-234). Thousand Oaks: Sage Publications.

Foster, H. 1996. The Artist as Ethnographer. The Return of the Real (pp. 171-204). Cambridge, MA: The MIT Press.

Foster, H. 1995. The Artist as Ethnographer?. Traffic in Culture (ed. G. Marcus and F. Myer), Berkley: University of California Press, pp. 302-309.

Frieling, R. 2008. The Art of Participation: 1950 to now, London; San Francisco; Thames \& Hudson; San Francisco Museum of Modern Art

Green, C. 2001. The third hand: collaboration in art from conceptualism to postmodernism. Sydney: UNSW Press.

Hebdige, D. 1979. Subculture: The Meaning of Style. London: Routledge.

Horst, H. and D. Miller (eds.) 2012, Digital Anthropology, Berg, London.

Horst, H., Hjorth, L. and J. Tacchi. 2012. 'Rethinking ethnography: An introduction', Media International Australia 145: 86-93.

Ingold, T. 2008. 'Bindings Against Boundaries: Entanglements Of Life In An Open World'. Environment And Planning A, 40: pp. 1796-1810.

Kester, G. 2011. The One and the Many: Contemporary Collaborative Art in a Global Context, Duke University Press.

Kester, G. 2010. www.greenmuseum.org

Kester, G. 2006. 'Reply' Artforum, May, pp. 22-23.

King, N. \& Hanru, H. 2013. 'Machines of Knowledge and Experimentation' Art Monthly, April, pp. 19-21.

Knowles, J.G. \& Cole, A.L. 2008. Handbook of the Arts in Qualitative Research: Perspectives, Methodologies, Examples, and Issues. Los Angeles: Sage.

Jenkins, H. 2009. Confronting the Challenges of Participatory Culture: Media Education for the 21st Century. Cambridge, MA: The MIT Press.

Lassiter, L. E. 2005. The Chicago Guide to Collaborative Ethnography. Chicago: The University of Chicago Press.

Lee, W.C and L Hjorth. 2011. 'Nostalgia for the Dial-up Modem: Cultures in Transition', Broadsheet December: 256-258.

Manovich, L. 2001. The language of new media. Cambridge, Mass.: MIT Press.

Massey, D. 2005, For Space, Sage, London.

Meskimmon, M. 2010. Contemporary Art and the Cosmopolitan Imagination. 
London: Routledge.

Milner, R. 2013. 'Treasure Hunting in the Waters beneath Shibuya'. Pingmag. http://pingmag.jp/2013/06/10/shibuya-underground-streams/. Accessed 22 June 2013. Morley, D. 1992. Television, Audiences and Cultural Studies, Routledge, London.

Nightingale, V. 2012. 'Media Ethnography and the disappearance of communication theory'. Media International Australia 145: 94-102.

Papastergiadis, N. 2012. Cosmopolitanism and Culture. Cambridge, UK: Polity Press Papastergiadis, N. 2011. Spatial Aesthetics: Art, Place and the Everyday, Institute of Network Cultures

Pink, S. 2009. Doing Sensory Ethnography, London: Sage

Pink, S. 2006. Doing Visual Ethnography, London: Sage

Silverstone, R. 1990. 'Television and Everyday Life: Towards an Anthropology of the Television Audience', in Public Communication: The New Imperatives, Future Directions for Media Research, M. Ferguson (ed.), Sage, London.

Silverstone, R. and Hirsch, E. (eds.), 1992. Consuming Technologies: Media and Information in Domestic Spaces, Routledge, London.

Storer, R. 2009. 'The world and the studio'. The 6th Asia Pacific Triennial of Contemporary Art (pp. 58-64). Brisbane: Queensland Art Gallery.

Wilken, R. \& G. Goggin (eds.) 2012. Mobile Technology and Place, New York: Routledge.

${ }^{1}$ Spatial Dialogue: Public Art and Climate Change is a three-year (2010-2013) Australian Research Council Linkage Project based at RMIT University with industry partners Grocon and Fairfax Media.

${ }^{2}$ For example, see Tokyo mobile geocaching game, keitai mizu, using Twitter and Instagram to get players to explore the invisible rivers running under Tokyo. http://spatialdialogues.net/tokyo/keitaimizu/

${ }^{3}$ The Boat People Association (BPA) comprises of architects, urban planners and artists (http://boatpeopleassociation.org). They organize events to draw attention to Tokyo's ignored and forgotten rivers.

${ }^{4}$ (see http://spatialdialogues.net/tokyo/shibuya/).

5 (www.facebook.com/TransformingTopographies)

${ }^{6}$ (see www.alternativearchive.com/ouning)

${ }^{7}$ (www.aucklandtriennial.com/about/theme). 